\title{
Go3R - Semantic Internet Search Engine for Alternative Methods to Animal Testing
}

\author{
Ursula G. Sauer ${ }^{1 *}$, Thomas Wächter ${ }^{2,4 *}$, Barbara Grune ${ }^{3}$, Andreas Doms ${ }^{2}$, \\ Michael R. Alvers ${ }^{4}$, Horst Spielmann ${ }^{3}$ and Michael Schroeder ${ }^{2}$ \\ ${ }^{1}$ Scientific Consultancy - Animal Welfare, Neubiberg/Munich, Germany; ${ }^{2}$ Bioinformatics Group, Biotechnology Center, \\ Technische Universität, Dresden, Germany; ${ }^{3}$ National German Centre for Documentation and Evaluation of Alternatives to \\ Animal Experiments, Federal Institute for Risk Assessment, Berlin, Germany; ${ }^{4}$ Transinsight GmbH, Dresden, Germany
}

\begin{abstract}
Summary
Consideration and incorporation of all available scientific information is an important part of the planning of any scientific project. As regards research with sentient animals, EU Directive 86/609/EEC for the protection of laboratory animals requires scientists to consider whether any planned animal experiment can be substituted by other scientifically satisfactory methods not entailing the use of animals or entailing less animals or less animal suffering, before performing the experiment. Thus, collection of relevant information is indispensable in order to meet this legal obligation. However, no standard procedures or services exist to provide convenient access to the information required to reliably determine whether it is possible to replace, reduce or refine a planned animal experiment in accordance with the 3 Rs principle. The search engine Go3R, which is available free of charge under http://Go3R.org, runs up to become such a standard service. Go3R is the world-wide first search engine on alternative methods building on new semantic technologies that use an expert-knowledge based ontology to identify relevant documents. Due to Go3R's concept and design, the search engine can be used without lengthy instructions. It enables all those involved in the planning, authorisation and performance of animal experiments to determine the availability of non-animal methodologies in a fast, comprehensive and transparent manner. Thereby, Go3R strives to significantly contribute to the avoidance and replacement of animal experiments.
\end{abstract}

Keywords: 3Rs principle, replacement, reduction, refinement, information retrieval, literature search, animal testing alternatives, REACH, semantic search technology

\section{Introduction - the role of information retrieval for the application of the 3Rs principle}

In 2007, over 2.6 Million vertebrate animals were used in animal experiments and other scientific procedures in Germany (BMELV, 2007). In comparison to the previous year, this is an increase by more than 91,000 animals. The most significant increase was recorded in the area of fundamental biomedical research. In addition, the new EU Chemicals Regulation REACH is expected to lead to an EU-wide increase in the numbers of animals used of up to 400,000 animals per year (Höfer et al., 2004), which would result in a financial burden of up to 5.4 Billion Euro (Fauser, 2007).

EU Directive 86/609/EEC for the protection of laboratory animals (Commission of the European Communities, 1986) obliges scientists to consider whether any planned animal experiment can be substituted by other scientifically satisfactory methods not entailing the use of animals or entailing less animals or less animal suffering, before performing the experiment. The ongoing revision of EU Directive 86/609/EEC is expected to lead to even more stringent rules regarding the evaluation of the indispensability of animal experiments in the course of licensing procedures (TEWG, 2003; Commission of the European Communities, 2008).

Thus, the replacement, reduction and refinement of animal experiments in accordance with the 3Rs principle (Russell and Burch, 1959) is a mandatory obligation - morally, legally, scientifically and also economically. To meet this obligation, scientists must consult the relevant scientific literature in respect to potential alternative methods prior to conducting any experimental study using laboratory animals.

Consideration and incorporation of all available scientific information is a crucial part in the planning of any scientific project. As regards the question of whether or not to perform an animal experiment in the course of a planned biomedical research project, it is not only scientific standard, but also a legal 
requirement to base this decision on the best available information. However, this scientific standard and legal obligation can only be met if all those involved in the planning, licensing and performance of biomedical research are able to obtain all available relevant information on alternative methods in accordance to the 3Rs principle. This intricacy demonstrates how closely the request to replace, reduce and refine animal experiments is connected to information retrieval and, as a result, information technology.

The core of any scientific strategy or political incentive to refine, reduce and replace animal experiments lies in the availability of relevant information regarding alternative methods.

It is against this background that the Go3R project was initiated in the summer of 2007. In a feasibility study funded by the National German Centre for Documentation and Evaluation of Alternatives to Animal Experiments (ZEBET) at the Federal Institute for Risk Assessment (BfR) in Berlin, Transinsight Gm$\mathrm{bH}$, Dresden, in co-operation with the Biotechnology Center of the Technical University Dresden, ZEBET at the BfR, Berlin, and Scientific Consultancy - Animal Welfare, Neubiberg/Munich, set out to develop Go3R, a 3Rs knowledge-based internet search engine, and to evaluate whether this new semantic technology tool could serve to improve internet inquiries on alternative methods. As a result of the feasibility study, a prototype of the search engine Go3R has been made available online via http://Go3R.org free of charge in April 2008.

Go3R is not a database. Go3R is a web-based search engine that actively retrieves $3 R$ s relevant information. It provides the search result automatically linked to an "intelligent table of contents". Thereby, Go3R actively supports the user in finding information on alternative methods that is available on the internet.

The article at hand presents the scientific rationale and the resulting framework of the Go3R search engine.

\section{State of the art and current technological problems in retrieving information on alternative methods from the internet}

Currently, the procedure of determining the availability or non-availability of 3 Rs methods - as required by law whenever a scientist plans to perform an animal experiment - is complex and the different steps taken by the scientist in pursuing this task are oftentimes not transparent to others. More

\footnotetext{
1 http://agricola.nal.usda.gov/

2 http://www.fao.org/Agris/

$3 \mathrm{http}: / /$ www.biosis.org/

4 http://www.cabi.org/datapage.asp?iDoclD=165

5 http://www.embase.com/

6 http://www.ncbi.nlm.nih.gov/sites/entrez?db=pubmed

$7 \mathrm{http}: / /$ www.dimdi.de/static/de/db/dbinfo/zt00.htm

8 http://ecvam-dbalm.jrc.ec.europa.eu/

9 http://ec.europa.eu/environment/chemicals/lab_animals/home_en.htm

$10 \mathrm{http}: / /$ ecb.jrc.it/

11 http://www.coe.int/T/E/Legal_affairs/Legal_co-operation/Biological_safety, use_of_animals/Laboratory_animals/

12 http://www.efsa.europa.eu/EFSA/efsa_locale-1178620753812_home.htm
}

than 50 Million potentially relevant documents are scattered across the internet, patent databases, literature databases and intranets. Classical search technologies search exactly what is asked for without understanding the meaning of the search terms or which information might be relevant for the search query. Therefore, they are unable to find alternatives that the user has not explicitly searched for. Finally, there are no methodologies to ensure that scientists, animal welfare officers, and authorities truly base their decisions on all available relevant information.

In the following, these problems are to be explained in further detail.

\subsection{Range of biomedical information available in the internet}

A large variety of databases and websites with information on alternative methods exists (Hakkinen and Green, 2002). This includes classical databases, such as AGRICOLA ${ }^{1}$, AGRIS $^{2}$, BIOSIS Previews ${ }^{3}$, CAB Abstracts ${ }^{4}$, EMBASE ${ }^{5}$ and PubMed/ MEDLINE $^{6}$. Furthermore, specialized added-value alternatives databases, such as AnimAlt-ZEBET ${ }^{7}$ and ECVAM/DB-ALM ${ }^{8}$, and an abundance of websites with information on animal experiments and alternatives or measures in line with the 3Rs principle are available, such as the websites of DG Environment of the EU Commission ${ }^{9}$, the Consumer Products Quality and Safety Unit, formerly known as the European Chemicals Bureau $^{10}$, Council of Europe ${ }^{11}$, European Food Safety Authority $^{12}$, Animal Welfare Information Center $^{13}$, AltTox ${ }^{14}$, Fund for the Replacement of Animals in Medical Experiments ${ }^{15}$, UK National Centre for the Replacement, Refinement and Reduction of Animals in Research ${ }^{16}$, Swiss Federal Agency for Veterinary Affairs ${ }^{17}$, German National Ministry for Education and Research ${ }^{18}$, German Federal Ministry for Nutrition, Agriculture and Consumer Protection ${ }^{19}$, Netherlands Centre for Alternatives to Animal Use ${ }^{20}$, Netherlands National Institute for Public Health and Environment ${ }^{21}$, Federation of European Laboratory Animal Science Associations ${ }^{22}$.

Such websites contain very diverse and unequally processed information - and oftentimes only concerning certain aspects of the 3Rs concept - and mostly have to be queried and scanned one-by-one by the searching scientist. Endeavours to concentrate 3Rs information on the internet do exist: Altweb - "the global clearinghouse for information on alternatives to animal testing" 23 is a website compiling and categorising an abundance of 3 Rs relevant information.

\footnotetext{
13 http://awic.nal.usda.gov/nal_display/index.php?info_center=3\&tax_level=1

$14 \mathrm{http}: / /$ www.alttox.org/

15 http://www.frame.org.uk/

16 http://www.nc3rs.org.uk/

17 http://www.bvet.admin.ch/themen/tierschutz/00777/00778/index. html?lang=de

$18 \mathrm{http}: / /$ www.bmbf.de/de/1040.php

19 http://www.bmelv.de/cln_045/nn_751684/DE/07-SchutzderTiere/

Tierschutz/_tierschutz_node.html_nnn=true

$20 \mathrm{http}: / /$ www.vet.uu.nl/nca/information/about_the_nca

21 http://www.rivm.nl/en/

22 www.felasa.eu/

23 http://altweb.jhsph.edu/
} 


\subsection{Internet searches in the area of alternative methods}

It is the inherent challenge of any search to find those documents in the vast pool of different information resources that are relevant for replacing, reducing and refining planned animal experiments. This problem becomes even more evident, when looking at the concrete amounts of data available on the internet. For instance, Pubmed/MEDLINE encompasses 18,590,000 documents (as of 01/2009); and EMBASE encompasses 12,773,576 documents (as of 01/2009). Both databases are updated every day. Even though the contents of different literature databases overlap, they are far from being identical, because different journals are indexed by different databases.

Furthermore, the indexing of publications and other information on alternative methods is limited by the following situation: During indexing, only the keywords of a given publication are being used, while the question if the methodologies depicted in the publication might be relevant for replacing or reducing animal experiments is not taken into consideration ${ }^{24}$. This implies that articles which do not explicitly mention that they present an alternative method will not be indexed as animal use alternatives. Own surveys (Grune et al., 2004) confirm this observation (see Tab. 1).

In search queries performed in five large biomedical literature databases, the different search terms for "alternative methods" and the term for "monoclonal antibodies" were combined. The numbers of documents retrieved ranged between 0 and 11. In comparison, there are 79 publications that ZEBET has recorded for the scientific subject of "replacement of the ascites mouse for the production of monoclonal antibodies". This shows that a large proportion of relevant publications were not identified in the search queries. To overcome this problem, a good search strategy would have to include a large number of terms that are related to the given search query.

This example reveals the challenges scientists face when using conventional search engines: In order to develop a reliable search strategy for their specific question, they have to select suitable search terms, have to handle the search operators correctly, have to select the relevant information from within large amounts of documents retrieved which always includes the danger of missing relevant information. Additionally, all of these issues have to be observed for each individual information source used.

A fundamental problem regarding searches is the selection of those terms that are to be searched for in the data pool. If the terms selected are too general, the numbers of documents retrieved will be far too large; and the documents are not sufficiently relevant. If the terms are too specific, important documents will be excluded from the list of results.

\section{Improving internet searches with semantic search technologies}

The problems inherent to classical literature searches can be overcome with the use of new semantic search technologies. Based on specific so-called ontologies, networks of relevant terms and concepts, semantic search technologies present search results in a structured form, accompanied by an intelligent table of contents. The searcher can use this table of contents to navigate through the search result and quickly extract those pieces of information that are relevant to him.

24 Nelson, S. J., The Alternative Project http://www.nlm.nih.gov/mesh/presentations/publicr/ppframe.htm

Tab. 1: Numbers of retrieved documents on alternative methods and monoclonal antibodies in MEDLINE, EMBASE, AGRIS, CAB Abstracts and AGRICOLA (search queries performed in 2002)

\begin{tabular}{|c|c|c|c|c|c|}
\hline Search terms & $\begin{array}{l}\text { MEDLINE } \\
\text { (7.8 Mio } \\
\text { documents) }\end{array}$ & $\begin{array}{l}\text { EMBASE } \\
\text { (6.9 Mio } \\
\text { documents) }\end{array}$ & $\begin{array}{l}\text { AGRIS } \\
\text { (2 Mio } \\
\text { documents) }\end{array}$ & $\begin{array}{l}\text { CAB Abstracts } \\
\text { (4.3 Mio } \\
\text { documents) }\end{array}$ & $\begin{array}{l}\text { AGRICOLA } \\
\text { (3.7 Mio } \\
\text { documents) }\end{array}$ \\
\hline animal testing alternatives & 1,023 & 0 & 418 & 213 & 968 \\
\hline animal testing reduction & 0 & 27 & 0 & 0 & 88 \\
\hline animal testing refinement & 0 & 19 & 0 & 0 & 45 \\
\hline animal testing replacement & 0 & 21 & 0 & 0 & 439 \\
\hline animal use alternatives & 33 & 0 & 1 & 1 & 345 \\
\hline animal use reduction & 0 & 0 & 0 & 1 & 213 \\
\hline animal use replacement & 0 & 0 & 0 & 0 & 112 \\
\hline animal use refinement & 0 & 0 & 0 & 0 & 253 \\
\hline Total of documents retrieved & 1,056 & 67 & 419 & 215 & 2,463 \\
\hline Monoclonal antibod?* & 109,535 & 125,467 & 5,532 & 17,332 & 5,188 \\
\hline $\begin{array}{l}\text { Monoclonal antibod?* AND } \\
\text { Total Hits for alternative methods }\end{array}$ & 11 & 0 & 3 & 6 & 11 \\
\hline
\end{tabular}

* The term "monoclonal antibodies" was truncated in order to retrieve singular and plural forms. 
Furthermore, semantic search engines understand what the user is searching for and even retrieve information that has not explicitly been sought for.

The following example of the question "which enzyme inhibits aspirin?" illustrates the difference between a conventional search in PubMed of the US National Library of Medicine and the National Libraries of Health ${ }^{25}$ and a knowledge-based search. In this example, the knowledge-based search was performed with GoPubMed (Doms and Schroeder, $2005)^{26}$, a general biomedical search engine developed by the project partner Transinsight $\mathrm{GmbH}$, Dresden, which already uses knowledge-based semantic technologies.

In PubMed, the search query "aspirin" results in a retrieval of 41,257 documents (P), which are presented in the form of a long list. Whereas GoPubMed delivers the same large amount of retrievals, they are accompanied by an "intelligent table of contents" (Fig. 1). By scrolling through this table of contents, the vast pool of documents can already be reduced to 30 documents with two clicks by filtering the search result with the category "Chemicals and Drugs" (\#1 in Fig. 1) and the term "Cyclooxygenase 2" (\#2). The first relevant document of this sub-list of 30 of the total of 41,257 documents would have been listed on position No. 410 of the PubMed list (\#3). The third document (\#4) of the mentioned sub-list then provides the answer that PGHS-2, a synonym to Cyclooxygenase 2, is inhibited by aspirin. In conclusion, the pre-sorting of documents provided by the knowledge-based search engine enables a speedy, precise and goal-oriented answering of the respective scientific question sought for.

\section{Infobox 1}

\section{How does a semantic, knowledge-based search engine improve internet searches?}

The scientific and technical basis of a semantic search engine is its underlying specific expert knowledge. In the search engine, this specific expert knowledge is captured within an ontology.

An ontology is an extensive and detailed network of - also hierarchically - grouped "concepts", such as subject areas, indicative for the respective field of research. If available, concepts also contain information about synonymous terminology. The ontology specifies the unambiguous meaning of relevant terms and depicts the complex relationships existing between them. With the help of such an ontology, the topic and content of any document can be semantically determined by the mapping of the unique pattern of concepts and terms utilised in it. Moreover, a semantic search engine "understands" what the user is looking for and extends search terms

\footnotetext{
25 http://www.ncbi.nlm.nih.gov/sites/entrez?db=pubmed

26 http://www.gopubmed.org
}

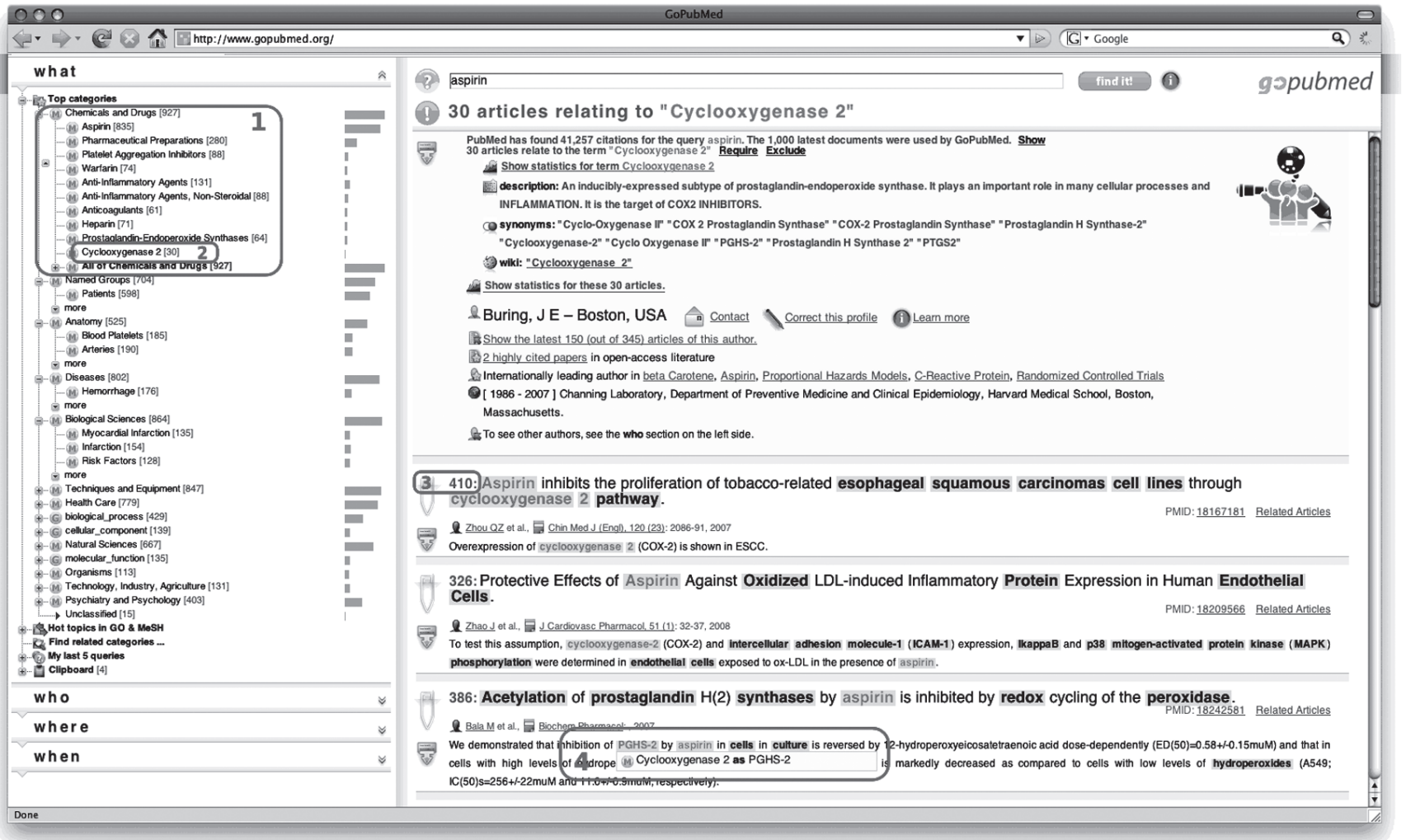

Fig. 1: Semantic search in GoPubMed to answer the question which enzyme inhibits aspirin? 
to categories, automatically taking into account the interrelation of terms and synonyms.

When a user launches a search query, the search engine maps the vocabulary used in the documents retrieved from the internet with the terms in the ontology, thereby determining not only the topics of the documents retrieved, but also their level of relevance with respect to the specific topic of the search query. When presenting the results of a search, the search engine uses the ontology to pre-sort the retrieved documents according to their respective pattern of concepts and by attributing them to delimited topics. The search result - the list of documents retrieved - is accompanied by an "intelligent table of contents" structuring the search result by representing it as the hit list of relevant concepts and terms used in the documents. The searcher can then use this table of contents to navigate through the "thicket of information" of his query result. By clicking on concepts and terms listed in the table of contents, the user will automatically see a sub-list of those documents assigned to the respective parts of the table of contents. This enables the user to quickly extract those parts of the search retrieval that are of interest to him.

\section{Development of the Go3R search engine}

In the course of a feasibility study funded by the National German Centre for Documentation and Evaluation of Alternatives to Animal Experiments (ZEBET) at the Federal Institute for Risk Assessment (BfR) in Berlin, Go3R, the first semantic internet search engine on alternative methods, was developed between the fall of 2007 and the summer of 2008. Technically, Go3R is based on the semantic search technology of GoPubMed (see Fig. 1 and Infobox 1). However, the specific ontology, the network of terms relevant for the given topic, is an essential part of a knowledge-based semantic search engine. Hence, an essential step in the development of the Go3R search engine during the feasibility study performed by Transinsight GmbH, ZEBET at the BfR, the Biotechnology Center of the Technical University Dresden and Scientific Consultancy - Animal Welfare has involved creating an initial seed 3Rs ontology by defining those concepts and terms that are relevant for alternative methods in accordance with the $3 \mathrm{Rs}$ principle and inferring the unique relations between them.

\subsection{Delineation of the scope of the Go3R ontology}

It was decided that the ontology should include information on 3Rs relevant methods from all areas of biomedical research in which animal experiments are performed. Accordingly, it was envisaged to start out by covering the following biomedical topics in the 3Rs ontology: animal production, cell biology, immunology, food hygiene, microbiology, molecular biology, parasitology, pharmacology, pharmacy, physiology, and toxicology. Furthermore, it was decided that the ontology should also include information on measures to improve the housing and the handling of laboratory animals, since such information can make a contribution to reducing the suffering of laboratory animals which in turn is relevant for the R "refinement".

Information on methods for which animals are killed or submitted to pain, suffering or distress for the education and ongoing education of students of biology, medicine and veterinary medicine were to be exempt from the ontology - at least for the time being. It was decided that the Go3R project should initially focus on $3 R$ s methods to animal experiments in accordance to the definition of the German Animal Welfare Act. Methods for which animals are killed or submitted to pain, suffering and distress for educational purposes do not count as "animal experiments" in accordance with the definition of the German Animal Welfare Act (German Federal Government, 2006).

\subsection{Development of the Go3R ontology}

A first frame for the $3 \mathrm{Rs}$ ontology was created by identifying existing ontologies and vocabularies relevant to the topic which were the AGRICOLA ${ }^{27}$ thesaurus and the branches diseases, anatomical structures and organs or chemical compounds from the Medical Subject Headings $(\mathrm{MeSH})^{28}$. With regard to the planned comprehensive navigation structure, it was considered necessary and meaningful to include both specifically 3Rs relevant terms in the ontology (e.g. "Local Lymph Node Assay") as well as thematic-defining terms (e.g. "dermatitis, allergic contact"). Parts of existing ontologies relating to 3Rs relevant terms on the housing and handling of laboratory animals as well as to physiological and psychological conditions of laboratory animals and to certain 3Rs methods (AGRICOLA) and to thematic-defining terms (MeSH) were linked to the Go3R Ontology. Descriptions of the existing ontologies modifications are given in Table 2. The ontology was further extended with newly composed 3Rs relevant terms. For this purpose, own expert knowledge and vocabulary from the documents in the ZEBET database AnimAlt ${ }^{29}$ were used.

As a preliminary framework requiring trial in practice, 28 different branches were defined and created for the Go3R ontology. It was distinguished between thematic-defining and directly $3 \mathrm{Rs}$ relevant branches (see Infobox 2 and Tab. 2).

\section{Infobox 2}

\section{Steps of the development of the Go3R ontology}

In order to sort the newly composed and conferred terms, the 3 Rs relevant and the thematic-defining vocabulary was grouped into concepts and a hierarchy of super- and subordinate concepts between the terms was defined. While forming the respective branches of the ontology, strict attention was paid to correctly adhering to the respective necessary subdividing steps and to labelling and defining the terms as pre-

27 AGRICOLA - Agricultural Online Access Thesaurus of the US National Agricultural Library, http://agricola.nal.usda.gov/

$28 \mathrm{MeSH}$ - Medical Subject Headings of the US National Library of Medicine, http://www.nlm.nih.gov/mesh/MBrowser.html

29 http://www.dimdi.de/static/de/db/dbinfo/zt00.htm 
cisely as possible so that correct correlations and mappings to superordinate terms could be achieved. In order to obtain a strictly hierarchical "parent-child" relationship between terms, all child terms and sub-child terms of a given branch of the ontology not only have to be children of their respective immediate superordinate term, but at the same time also sub-children of all higher direct superordinate terms of the respective higher terms of the given branch. Additionally, terms had to be labelled with sufficient precision so that they could only be assigned to their superordinate term and not to very different terms that might not even be part of the ontology. Finally, terms were attributed with synonyms, abbreviations, and textual definitions.

The assignment of superordinate and subordinate concepts revealed the necessity to create a further type of correlation between terms in the ontology in addition to the assignment of direct parent-child relationships. Thereby, an article in which e.g. a concrete 3 Rs method is not explicitly mentioned could still be recognized as relevant for the specific topic searched for in an indirect manner, for example if it mentions specific cells, endpoints or endpoint detection methods which would be relevant for the respective application.

\section{Word sense disambiguation}

Word sense disambiguation deals with relating the occurrence of a word in a text to a specific meaning, which is distinguishable from other meanings that can potentially be related to that same word (Martijn et al., 2005).

In some of the directly 3Rs relevant branches, the terms included are necessarily 3 Rs relevant (i.e. "Neutral Red Uptake Phototoxicity Test"). If such terms are included in a document, the respective information will necessarily be 3Rs relevant. In other branches, however, the terms listed can refer to 3 Rs relevant measures in documents, but - in respect to the given context - not necessarily so (e.g. the term "alternative" can be used in very many different contexts). Such branches and concepts therefore require diligent further processing of each individual term: First, the ontology has to include all commonly used synonyms of such terms. Additionally, each individual term has to be submitted to a thorough word sense disambiguation process (Xu et al., 2006). In this case the search engine has to learn to distinguish between a $3 \mathrm{R}$ relevant document containing the term "alternative" and a document, in which this term is used in a context unrelated to the 3 Rs principle.

Regarding word sense disambiguation, the terms "replacement", "reduction" and "refinement" present a special challenge for the search engine. While these terms evidently are central concepts of the 3 Rs principle, all three words are also used as general words in a large variety of very different contexts. Therefore these three terms require an especially detailed and specific word sense disambiguation in order to avoid retrieving a broad range of completely irrelevant documents in which the words "replacement", "reduction" and "refinement" are used in entirely unrelated contexts.

\section{Rs relevance filter}

In the ontology, the term "3Rs relevant" has been assigned a special status. It does not have any child terms and is the only term that the search engine does not search for directly in documents, i.e. the search engine does not highlight the term "3Rs relevant" in a document.

Instead, the term "3Rs relevant" is used as a signet to automatically grade the $3 \mathrm{Rs}$ relevance of the documents that were retrieved during the respective search query. Thus the term " 3 Rs relevant" serves as a filter.

Technically, the 3 Rs relevance filter categorises documents using a Machine Learning Technology called Maximum Entropy Method (Berger et al., 1996). The Maximum Entropy Method enables the filter to learn the characteristics of documents belonging to a certain pre-defined category by using documents as vectors of binary features with the aim to assign each document to a pre-defined category. Features can be textual occurrences of terms as well as meta information on documents such as the publishing journal or the year of publication.

In regard to the 3Rs relevance filter, the Maximum Entropy Method was trained using approx. 3,000 documents handannotated as being 3Rs relevant or not, thereby teaching the search engine to distinguish between 3Rs relevant and 3Rs irrelevant documents based on the words and document metainformation contained and associated with the documents. As a result, the 3 Rs filter, currently available in its beta version, highlights those documents in which methods or methodologies are depicted that can make a contribution towards replacing, reducing and refining animal experiments.

\section{Use of the Go3R ontology prototype and evaluation of use cases for an initial quality control}

The Go3R user interface available at http://Go3R.org is divided into two areas. The right hand side contains the search field for the search query. Search queries are typed in accordance to the same rules as for MEDLINE. The left hand side of the user interface provides the structure of the intelligent table of contents and has four sections, WHAT, WHO, WHERE and WHEN:

- WHAT - the ontology / intelligent table of contents itself, used for rapid semantic sorting of the documents retrieved,

- WHO - presenting a list of the authors of the publications retrieved,

- WHERE - presenting a list of the affiliations of the authors, useful for example to reveal institutions specialising in certain areas,

- WHEN - allowing to observe the developments of trends in research over time.

When performing a search query with Go3R, the search engine compares the terms and concepts of the ontology with the vocabulary used in the documents retrieved. It highlights relevant terms in the documents and presents these in the intelligent table of contents. The content of any document is semantically determined by 
Tab. 2: List of the 28 branches of the Go3R ontology prototype

\begin{tabular}{|c|c|c|c|}
\hline Ontology branch & Definition of terms listed in branch & $\begin{array}{l}\text { Examples for terms included in } \\
\text { the branch }\end{array}$ & Comment \\
\hline 3Rs Institutions & $\begin{array}{l}\text { Institutions with the primary mission } \\
\text { to make a contribution towards } \\
\text { replacing, reducing, or refining animal } \\
\text { tests and animal experiments. }\end{array}$ & e.g. "ZEBET", "ECVAM" & Terms are directly 3 Rs relevant. \\
\hline $\begin{array}{l}\text { 3Rs Methods in } \\
\text { the Life Sciences }\end{array}$ & $\begin{array}{l}\text { Concrete } 3 \text { Rs test methods } \\
\text { sorted in accordance to their area of } \\
\text { use in the life sciences }\end{array}$ & $\begin{array}{l}\text { e.g. the Neutral Red Uptake } \\
\text { Phototoxicity Test is listed under "3Rs } \\
\text { in toxicology - 3Rs in photoirritation" } \\
\text { and the HPLC method for Calcitonin } \\
\text { determination under "3Rs in pharmacy" }\end{array}$ & Terms are directly $3 R$ s relevant. \\
\hline 3Rs Relevant & $\begin{array}{l}\text { Special term in the ontology without } \\
\text { child-terms }\end{array}$ & $\begin{array}{l}\text { No child-terms due to special } \\
\text { status of this term }\end{array}$ & $\begin{array}{l}\text { Filter with which the search engine } \\
\text { grades the 3Rs relevance of the } \\
\text { documents retrieved during a query }\end{array}$ \\
\hline $\begin{array}{l}\text { 3Rs Research } \\
\text { Projects }\end{array}$ & $\begin{array}{l}\text { Names of research projects pursuing } \\
\text { the primary goal to develop 3Rs test } \\
\text { methods }\end{array}$ & $\begin{array}{l}\text { e.g. ReProTect for the EU integrated } \\
\text { project aiming at developing "a novel } \\
\text { approach in hazard and risk } \\
\text { assessment of reproductive toxicity", } \\
\text { www.reprotect.eu }\end{array}$ & Terms are directly $3 R s$ relevant. \\
\hline $\begin{array}{l}\text { Animal Care and } \\
\text { Handling }\end{array}$ & $\begin{array}{l}\text { Procedures with which humans care } \\
\text { for animals or handle and manipulate } \\
\text { them }\end{array}$ & $\begin{array}{l}\text { e.g. "group housing", "ad libitum } \\
\text { feeding", "animal identification" or } \\
\text { "capturing of animals" }\end{array}$ & $\begin{array}{l}\text { Word sense disambiguation } \\
\text { required for each individual term }\end{array}$ \\
\hline $\begin{array}{l}\text { Animal Conditions, } \\
\text { Physiological } \\
\text { or Psychological }\end{array}$ & $\begin{array}{l}\text { Desirable or undesirable physiological } \\
\text { or psychological states of animals }\end{array}$ & $\begin{array}{l}\text { e.g. "animal behaviour", "animal } \\
\text { welfare", "animal distress" }\end{array}$ & $\begin{array}{l}\text { Word sense disambiguation } \\
\text { required for each individual term }\end{array}$ \\
\hline $\begin{array}{l}\text { Animal } \\
\text { Experiments }\end{array}$ & $\begin{array}{l}\text { Animal models, animal test methods } \\
\text { and names of in vivo refinement or } \\
\text { reduction methods }\end{array}$ & $\begin{array}{l}\text { e.g. "disease models, animal", } \\
\text { "guinea-pig maximisation test", } \\
\text { "fixed dose procedure" }\end{array}$ & Thematic-defining branch \\
\hline Animal Species & $\begin{array}{l}\text { Species of invertebrate and vertebrate } \\
\text { animals. In the case of vertebrate } \\
\text { animals, emphasis is given to } \\
\text { mentioning those species that are } \\
\text { regularly used in experiments and for } \\
\text { other scientific procedures. }\end{array}$ & $\begin{array}{l}\text { e.g. "rabbit", "rodent", } \\
\text { "non-human primate" }\end{array}$ & $\begin{array}{l}\text { Word sense disambiguation is } \\
\text { required to instruct the search } \\
\text { engine to distinguish whether } \\
\text { reference to animal species in a } \\
\text { document means that the } \\
\text { respective animals were used in } \\
\text { vivo or that e.g. primary cells of } \\
\text { such animals were used in vitro. }\end{array}$ \\
\hline $\begin{array}{l}\text { Animal Use } \\
\text { Alternatives }\end{array}$ & $\begin{array}{l}\text { Classification of animal use } \\
\text { alternatives in accordance to their } \\
\text { correlation to the } 3 R \text { s principle. }\end{array}$ & $\begin{array}{l}\text { "Reduction alternative", "refinement } \\
\text { alternative" and "replacement } \\
\text { alternative" }\end{array}$ & $\begin{array}{l}\text { In contrast to the branch " } 3 R \text { s } \\
\text { methods in the life sciences", in } \\
\text { which concrete test methods are } \\
\text { listed in accordance to their areas } \\
\text { of use, the branch "animal use } \\
\text { alternatives" merely maps the } \\
\text { fundamental distinction between } \\
\text { "replacement methods", } \\
\text { "reduction methods" and } \\
\text { "refinement methods". }\end{array}$ \\
\hline Bioethics & $\begin{array}{l}\text { Terms relating to the } 3 \text { Rs principle as } \\
\text { such as well as to other bioethical } \\
\text { topics as the case may be. }\end{array}$ & "3Rs principle" & \\
\hline $\begin{array}{l}\text { Biological } \\
\text { Material \& } \\
\text { Organisms for } \\
\text { Animal Use } \\
\text { Alternatives }\end{array}$ & $\begin{array}{l}\text { Cell, tissues, organs and single-cell } \\
\text { organisms employed in non-animal } \\
\text { test methods. }\end{array}$ & $\begin{array}{l}\text { e.g. cultivated primary cells or } \\
\text { specific cell lines, organ and tissue } \\
\text { cultures, reconstituted organs }\end{array}$ & $\begin{array}{l}\text { Documents in which reference is } \\
\text { made to specific cell lines, for } \\
\text { instance, have a strong likelihood } \\
\text { of containing } 3 \text { Rs relevant } \\
\text { information. }\end{array}$ \\
\hline
\end{tabular}


Table 2 (continued): List of the 28 branches of the Go3R ontology prototype

\begin{tabular}{|c|c|c|c|}
\hline Ontology branch & Definition of terms listed in branch & $\begin{array}{l}\text { Examples for terms included in } \\
\text { the branch }\end{array}$ & Comment \\
\hline $\begin{array}{l}\text { Body Systems \& } \\
\text { Structures }\end{array}$ & Anatomical systems and structures. & $\begin{array}{l}\text { e.g. "gastrointestinal tract", } \\
\text { "blood vessels" }\end{array}$ & $\begin{array}{l}\text { MeSH branch "Body Systems \& } \\
\text { Structures" and additional terms, } \\
\text { e.g. relevant terms relating to } \\
\text { veterinary medicine that were not } \\
\text { contained in MeSH. }\end{array}$ \\
\hline $\begin{array}{l}\text { Diseases \& } \\
\text { Symptoms }\end{array}$ & $\begin{array}{l}\text { Disorders of structure of function of } \\
\text { the human or animal body. }\end{array}$ & e.g. "endocarditits", "leukaemia" & $\begin{array}{l}\text { MeSH branch "Diseases \& } \\
\text { Symptoms" with some addition } \\
\text { terms where needed. }\end{array}$ \\
\hline $\begin{array}{l}\text { In Vitro Culture } \\
\text { Technology \& } \\
\text { Equipment }\end{array}$ & $\begin{array}{l}\text { Concepts relating amongst others } \\
\text { to (1) in vitro cell culture systems, } \\
\text { (2) cell culture additives, ( } 3 \text { ) cell } \\
\text { culture equipment or (4) manipulations } \\
\text { with cells. }\end{array}$ & $\begin{array}{l}\text { e.g. (1) "suspension culture", } \\
\text { (2) "serum free medium", } \\
\text { (3) "perfusion systems", } \\
\text { (4) "cell cryoconservation" }\end{array}$ & $\begin{array}{l}\text { In the respective context, such } \\
\text { terms refer to } 3 R \text { s relevant } \\
\text { information with a high probability. }\end{array}$ \\
\hline $\begin{array}{l}\text { In Vitro } \\
\text { Experimental } \\
\text { Design }\end{array}$ & $\begin{array}{l}\text { Terms describing the experimental } \\
\text { design of in vitro test methods, } \\
\text { including (1) test endpoints, } \\
\text { (2) endpoint detection methods and } \\
\text { (3) cell culture test scoring procedures. }\end{array}$ & $\begin{array}{l}\text { e.g. (1) "cell viability", "DNA damage", } \\
\text { "enzyme induction", (2) "neutral red } \\
\text { uptake" and (3) "half maximal inhibitory } \\
\text { concentration, IC50". }\end{array}$ & $\begin{array}{l}\text { In a given context, such terms } \\
\text { can refer to } 3 \text { Rs relevant } \\
\text { information. }\end{array}$ \\
\hline
\end{tabular}

\begin{tabular}{lll}
\hline In Vivo & Terms describing the experimental & $\begin{array}{l}\text { e.g. the dosage of animals, or the } \\
\text { scoring of test results } \\
\text { Design }\end{array}$
\end{tabular}
This branch requires further elaboration to put emphasis on terms that make reference to the application of humane endpoints or to measures towards reducing numbers of animals used in the procedures.

\begin{tabular}{ll}
\hline Laboratory Animal & $\begin{array}{l}\text { The science and technology dealing } \\
\text { with the procurement, breeding, care, } \\
\text { health, and selection of animals used } \\
\text { in biomedical research and testing. }\end{array}$
\end{tabular}

This branch requires further development to include relevant terms relating to the science dealing with the care and use of animals used in biomedical research and testing.

Laboratory Specific types of laboratory animals. e.g. "specific pathogen-free animals"
Animals

Further experience in practice is required to establish its usefulness in practice and to adapt it accordingly.

\begin{tabular}{lll}
\hline Life Sciences & $\begin{array}{l}\text { Terms describing the sciences } \\
\text { concerned with the study of living } \\
\text { organisms. }\end{array}$ & $\begin{array}{l}\text { e.g. "food hygiene", "microb } \\
\text { "toxicology" }\end{array}$ \\
\hline $\begin{array}{l}\text { Method } \\
\text { Specification }\end{array}$ & $\begin{array}{l}\text { Attributes describing types of } \\
\text { methods. }\end{array}$ & e.g. "in vitro" and "in vivo"
\end{tabular}

This is a thematic-defining branch from MeSH mapping concepts on life science terms relevant for the issue of $3 R$ s methods."

Many documents describing cell culture test methods, for instance, include the term "in vitro" so that the narrowing down of search results to this term might enable a first broad selection of possibly relevant articles.

\begin{tabular}{lll}
\hline Methodology & $\begin{array}{l}\text { Terms and concepts for specific test } \\
\text { methodologies }\end{array}$ & $\begin{array}{l}\text { e.g. "enzyme-linked immunoassay", } \\
\text { "high performance liquid } \\
\text { chromatography" }\end{array}$
\end{tabular}

This branch is conceived to supplement the branch " $3 R$ s in the Life Sciences" aiming to enable documents describing specific methodologies to be retrieved independently from their application of use.

\begin{tabular}{ll}
\hline $\begin{array}{l}\text { Product Properties } \\
\text { \& Effects }\end{array}$ & Characteristics of products and their \\
wanted or unwanted effects
\end{tabular}


Table 2 (continued): List of the 28 branches of the Go3R ontology prototype

\begin{tabular}{|c|c|c|c|}
\hline Ontology branch & Definition of terms listed in branch & $\begin{array}{l}\text { Examples for terms included in } \\
\text { the branch }\end{array}$ & Comment \\
\hline $\begin{array}{l}\text { Product Testing } \\
\text { \& Assessment }\end{array}$ & $\begin{array}{l}\text { Terms describing certain forms of } \\
\text { testing and assessment of products }\end{array}$ & $\begin{array}{l}\text { e.g. "efficacy testing", } \\
\text { "risk assessment" }\end{array}$ & \\
\hline Statistics & $\begin{array}{l}\text { Terms describing the science of } \\
\text { collecting, summarizing, and analyzing } \\
\text { data that are subject to random } \\
\text { variation. }\end{array}$ & $\begin{array}{l}\text { e.g. "predictive value", } \\
\text { "uncertainty factor" }\end{array}$ & $\begin{array}{l}\text { This branch, currently including } \\
\text { relevant on statistics from MeSH, } \\
\text { requires further elaboration to } \\
\text { include specific terms relating to } \\
\text { the statistical evaluation of test } \\
\text { results that are specifically relevant } \\
\text { for the 3Rs ontology. }\end{array}$ \\
\hline $\begin{array}{l}\text { Substances, } \\
\text { Preparations \& } \\
\text { Products }\end{array}$ & $\begin{array}{l}\text { Terms referring to both biological sub- } \\
\text { stances and industrially produced } \\
\text { substances, preparations and products }\end{array}$ & $\begin{array}{l}\text { Such terms enable subsorting search } \\
\text { results in accordance to specific } \\
\text { biological substances under } \\
\text { investigation (e.g. specific transmitters, } \\
\text { enzymes, etc., evaluated for instance } \\
\text { in biomedical studies) or in accordance } \\
\text { to the type of test substance } \\
\text { (heterocyclic compounds, polycyclic } \\
\text { compounds, etc.) used in toxicological } \\
\text { studies. }\end{array}$ & $\begin{array}{l}\text { This is a thematic-defining branch, } \\
\text { imported from MeSH. }\end{array}$ \\
\hline $\begin{array}{l}\text { Toxic Actions of } \\
\text { Substances }\end{array}$ & $\begin{array}{l}\text { Concepts and terms that describe } \\
\text { substances in regard to their category } \\
\text { of harmful action on living organisms }\end{array}$ & e.g. "irritant", "mutagene" & $\begin{array}{l}\text { This is a predominantly } \\
\text { thematic-defining branch, imported } \\
\text { from MeSH. }\end{array}$ \\
\hline $\begin{array}{l}\text { Toxicity Testing } \\
\text { Strategies, 3Rs }\end{array}$ & $\begin{array}{l}\text { Terms describing testing strategies } \\
\text { making a contribution to refining, } \\
\text { reducing or replacing animal testing } \\
\text { as such. }\end{array}$ & $\begin{array}{l}\text { e.g. "tiered testing strategy", } \\
\text { "integrated testing strategy" }\end{array}$ & $\begin{array}{l}\text { When such terms are used in a } \\
\text { document, the information is very } \\
\text { likely to be } 3 \text { Rs relevant. }\end{array}$ \\
\hline $\begin{array}{l}\text { Validation of Test } \\
\text { Methods }\end{array}$ & $\begin{array}{l}\text { Terms describing the different steps } \\
\text { and aspects of validation of test } \\
\text { methods. }\end{array}$ & $\begin{array}{l}\text { e.g. "reproducibility, test methods", } \\
\text { "predictivity, negative, test methods" }\end{array}$ & $\begin{array}{l}\text { In combination with further specific } \\
\text { terms, such terms can point to } 3 R s \\
\text { relevant documents. }\end{array}$ \\
\hline
\end{tabular}

the mapping of its unique pattern of concepts and of the terms utilised in it. The search engine also recognizes terms that are only indirectly related to the search query, i.e. specific cell lines, endpoints or endpoint detection methods that might be relevant for the given scientific application. Thereby, an article in which e.g. a concrete 3Rs method is not explicitly mentioned can still be recognized as relevant for the specific topic searched for. Additionally, the Go3R search engine has been provided with a 3 Rs relevance filter, currently available in its beta version, which automatically grades the 3Rs relevance of documents retrieved (see Infobox 2).

Since the development of the first ontology structure in the winter of 2007/2008, the given state of the ontology has been submitted to a continuous evaluation of its functionality in retrieving relevant $3 \mathrm{Rs}$ methods. This continuous quality control serves to evaluate whether using the ontology allows a comprehensive and targeted retrieval of 3Rs relevant information in regard to a given subject and, if not, which additional terms, ontology structures or search engine features are necessary to enable retrieving the missing 3 Rs relevant information.

In March 2008, the search query "Eye Irritation" was one of the first use scenarios performed to test the initial Go3R ontol- ogy prototype in practice. Infobox 3 presents the results of the evaluation of this use scenario and the lessons derived.

\section{Infobox 3}

Steps of the use scenario "search query - eye irritation"

The very general search query "Eye Irritation" was used to search for publications on methods with which the in vivo Draize eye irritation test on the rabbit eye might be replaced, reduced or refined, as the case may be. The search term was deliberately chosen to lack further terms narrowing down the search query so that a comprehensive picture of the capability and effectiveness of the search engine itself in narrowing down the search result in respect to 3Rs methods and methodologies could be obtained.

Additionally, the search query "Eye Irritation" was chosen as a first detailed use scenario since the ZEBET database AnimAlt ${ }^{30}$ lists a large variety of 3 Rs methods for the determination of eye irritating effects of substances and provides

30 http://www.dimdi.de/static/de/db/dbinfo/zt00.htm 
an abundance of literature references on this topic. The information provided for in the ZEBET database was taken as "reference data" to test whether the ontology would enable retrieval of the same amount of information.

For the following sixteen 3Rs methods to determine eye irritating effects of substances, separate entries in the ZEBET database exist: luminescent bacteria toxicity test (ZEBET40), red blood cell (RBC) test (ZEBET 30), chorioallantoic membrane vascular assay (CAMVA) (ZEBET 272), EYTEX (ZEBET 271), fluorescence leakage test (ZEBET 270), neutral red release (NRR) assay (ZEBET 265), neutral red uptake (NRU) cytotoxicity assay (ZEBET 26), chicken egg chorioallantoic membrane (HET-CAM) assay (ZEBET 25), silicon microphysiometer (ZEBET 245), human skin cell multilayer cultures (ZEBET 237), low volume eye test (LVET) (ZEBET 236), optical function of bovine lens (ZEBET 109), chicken enucleated eye test (CEET) (ZEBET 107), isolated rabbit eye (IRE) test (ZEBET 105), bovine corneal opacity and permeability (BCOP) assay (ZEBET 103), pollen tube growth test (ZEBET 101).

The search query "Eye Irritation" resulted in 565 documents retrieved with the search engine Go3R (as of 03/2008). In the resulting "intelligent table of contents", 31 of these 565 documents were listed in the ontology branch "3Rs Methods in the Life Sciences" under the term "3Rs in Toxicology". 29 of these
31 documents indeed contained information on 3Rs methods to determine eye irritating effects. They provided information on the following 12 of the 16 3Rs methods listed in the ZEBET database: NRU test, IRE test, HET-CAM, BCOP, NRR assay, human epithelial cell line tests, fluorescence leakage test, luminescent bacteria toxicity test, LVET, EYTEX, CAMVA, CEET. Additionally, documents were retrieved on TOPKAT and EpiOcular, for which there are no separate entries in the ZEBET database. Information on a further 3 Rs eye irritation test, the RPC test, was found in the ontology branch "Method specification - in vitro" (containing a sub-list of 80 retrievals).

Thus, the first prototype Go3R ontology allowed targeted retrieval of information on 13 of the 16 3Rs eye irritation methods listed in the ZEBET database.

At the same time, the search query showed that PubMed only covers approximately one third of the literature on 3Rs methods to determine eye irritating effects provided for in the ZEBET database. One reason for this discrepancy is that PubMed has only lately taken up indexing a number of $3 \mathrm{Rs}$ relevant journals (for instance, ALTEX and Toxicology In Vitro have been indexed as of the year 2000 and ATLA as of Jan/Feb 2001.) Other journals, such as In Vitro Toxicology (which was published from fall 1986/1987 until winter 1997) are not indexed by PubMed at all.

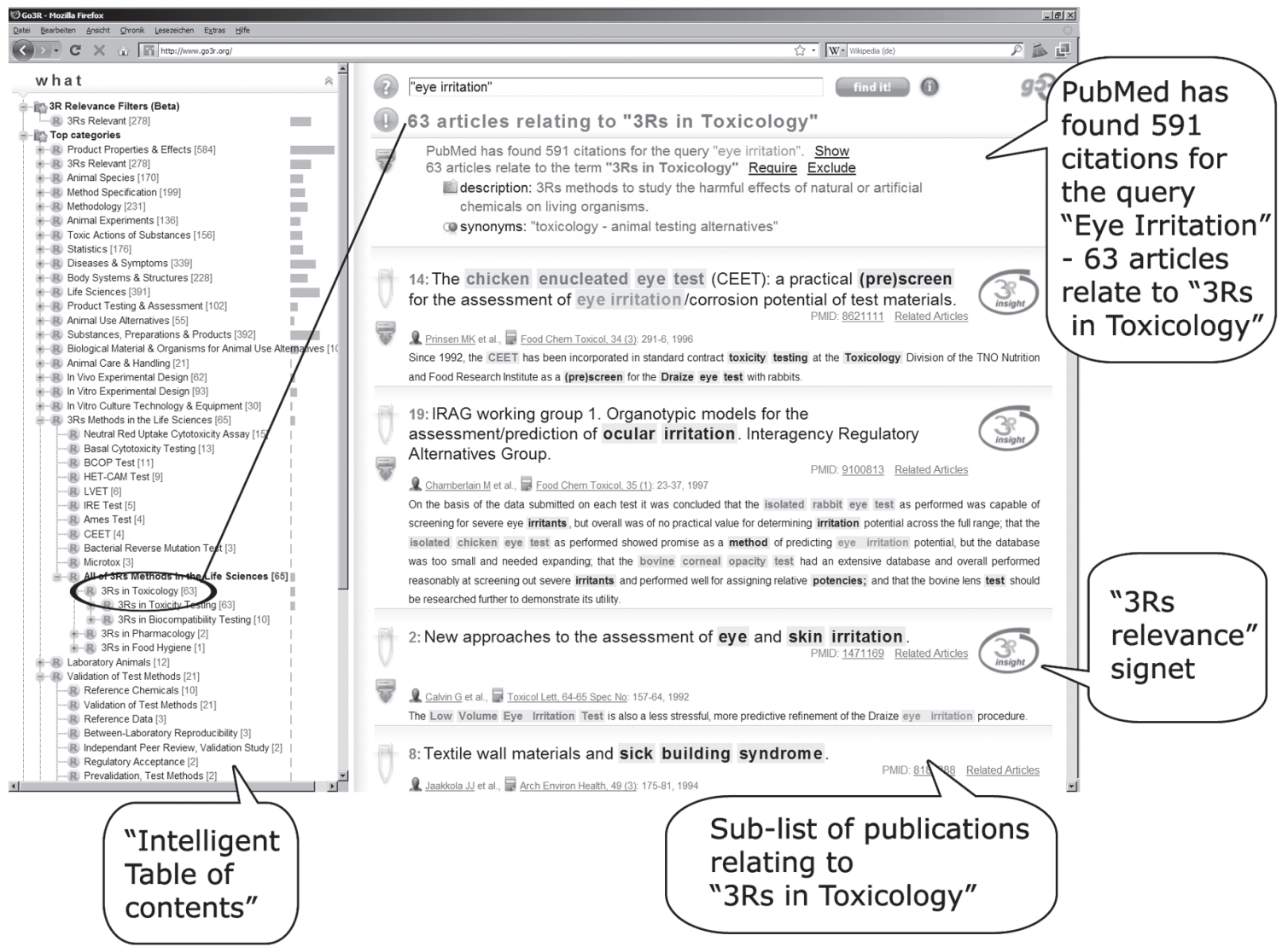

Fig. 2a: Go3R user interface with the search query "eye irritation" indicated in the search field.

The screenshot presents the sub-list of 63 articles relating to "3Rs in Toxicology" extracted from the full search retrieval of 591 citations found for the query "Eye Irritation" (as of 01/2009). 
As was mentioned above, two publications of the 31 documents of the search retrieval on "Eye Irritation" which Go3R listed under "3Rs in Toxicology" did not contain information on 3Rs eye irritation test methods. These two documents provided information on 3Rs methods for other endpoints instead: the "Local Lymph Node Assay" to determine sensitising effects and the "basal cytotoxicity test" to determine acute systemic toxicity. Nevertheless, the abstracts of both publications contained the term "Eye Irritation". As a result the search engine "correctly" retrieved these two publications during the search query "Eye Irritation" and listed them under the term "3Rs in Toxicology".

In conclusion, the Go3R search engine prototype was unable to retrieve information on three of the 163 Rs methods listed in the ZEBET database with the search query "Eye Irritation". To identify the reason for this, in a next step these three methods were explicitly searched for with the specific search queries "silicon microphysiometer", "optical function of bovine lens test" and "pollen tube growth test".

These specific search queries revealed that the respective publications presenting these three methods (as far as they were listed in PubMed at all) referred to the determination of eye irritating effects with terms and concepts that had not yet been included in the ontology, such as "ocular safety test- ing”, “irritancy screening", "irritating potential of ingredients of cosmetic formulations". These terms were included into the ontology in order to become able to retrieve such information via Go3R as well.

Figures $2 \mathrm{a}$ and $2 \mathrm{~b}$ illustrate the different steps of performing and evaluating the search query "Eye Irritation" with the search engine prototype Go3R in January 2009, after the experiences gained during the initial use of the search engine in March 2008 had already been taken into account. The 591 documents retrieved as a result of the search query are presented together with the intelligent table of contents. By clicking through this table of contents, the user can extract sub-lists relating to a topic that is of interest to him (e.g. the 63 articles relating to "3Rs in Toxicology", Fig. 2a). Within this sub-list, a further sub-list of 11 articles relates to the "BCOP test" (Fig. 2b). 3Rs relevant articles are automatically indicated with the " 3 Rs relevance signet" assigned by the 3Rs relevance filter (Fig. 2a, 2b).

The search query "Blood-Brain Barrier" was chosen as another example to test the Go3R ontology and search engine in retrieving relevant $3 \mathrm{Rs}$ information in the area of fundamental biomedical research. Again, the search term "Blood-Brain Barrier" was deliberately chosen to be very general lacking further

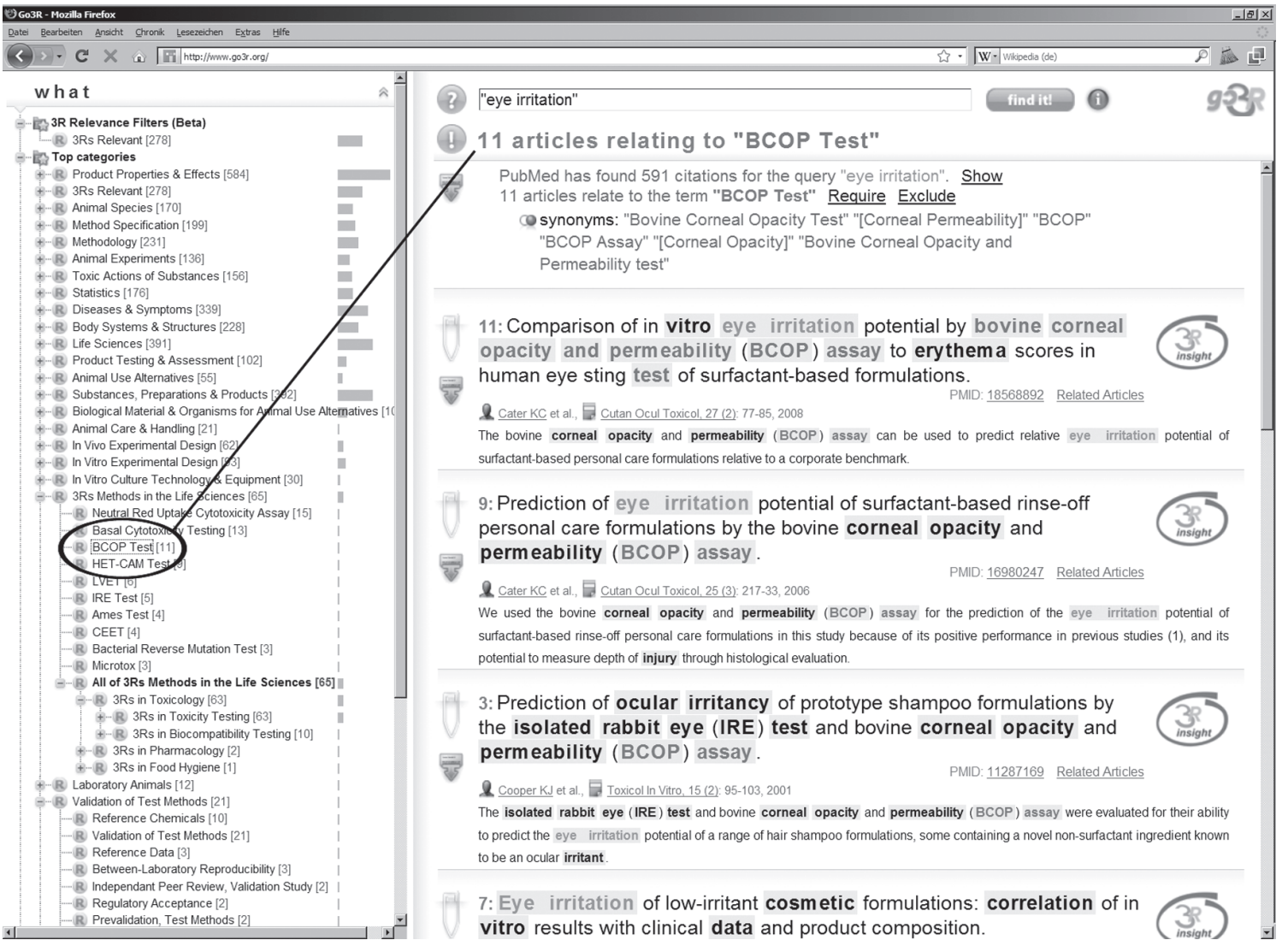

Fig. 2b: Within the sub-list of 63 articles related to "3Rs in Toxicology", a further sub-list of 11 articles relates to the "BCOP test" (as of 01/2009) 
terms narrowing down the search query to ensure that only the effectiveness of the Go3R search engine was tested.

In the classical search in PubMed, the search query "BloodBrain Barrier" resulted in a total of 24,351 documents (as of 01/2009), which, evidently, are presented in the form of a long list. Additional search steps are required to narrow down the number of hits in the search of 3Rs relevant documents. The same search query performed with Go3R (Fig. 3) also resulted in 24,351 documents, however, the accompanying "intelligent table of contents" allowed to quickly extract 45 articles relating to "In Vitro Blood-Brain Barrier Methods" from within this vast data pool.

\section{Discussion}

In April 2008, Go3R has been made available online free of charge at http://Go3R.org. It aims to enable all those involved in the planning, authorisation and performance of animal experiments to determine the existence of non-animal methodologies in a fast, comprehensive and transparent manner.
Go3R is the worldwide first internet search engine for alternative methods to animal experiments that uses innovative semantic search technologies.

Go3R is the first and currently only semantic tool with a specific focus on alternative methods. Recently, other semantic search technologies have been developed and made available online which also mine the tremendous pool of biomedical information in the internet. Nevertheless, the search benefit achieved by Go3R in retrieving information on alternative methods in accordance to the 3 Rs principle cannot be paralleled by any other of the currently available semantic search engines.

The most important difference highlighting the uniqueness of Go3R in searching for alternatives to animal experiments is its expert knowledge-based 3Rs specific ontology which specifically maps subjects and terms related to animal use alternatives. Thereby, retrieved information is classified with a focus on alternative methods in a meaningful manner.

In contrast, the ontology-based search engine GoPubMed (see above) covers general biomedical issues using the Gene Ontol$\operatorname{ogy}^{31}$ and the Medical Subject Headings $(\mathrm{MeSH})^{32}$. Therefore, it does not serve to specifically retrieve 3 Rs methods.

31 http://www.geneontology.org/

32 http://www.nlm.nih.gov/mesh/

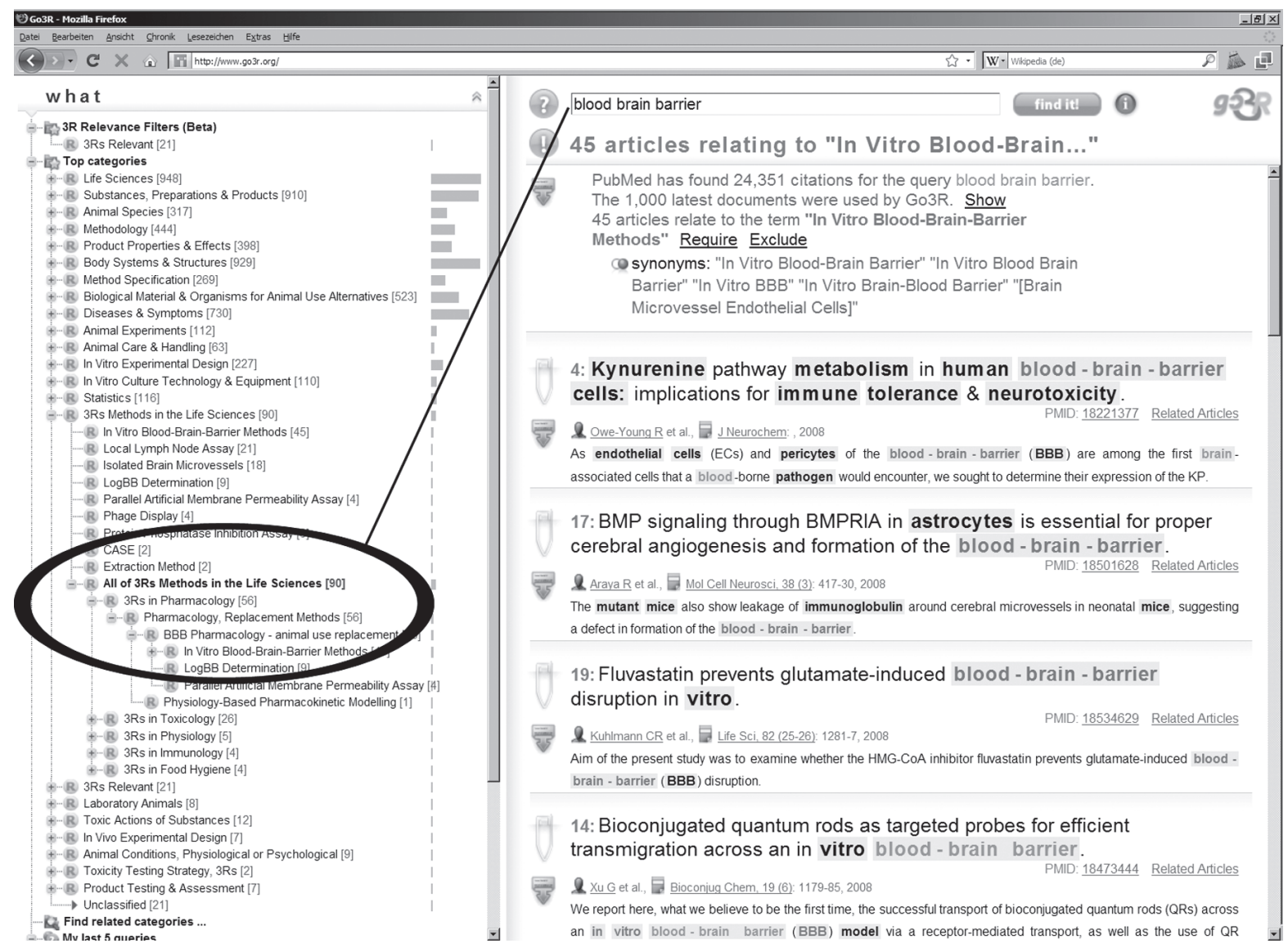

Fig. 3: Go3R user interface, with the search query.

"Blood-Brain Barrier" indicated in the search field. Within the respective sub-list, 45 articles related to "In Vitro Blood-Barrier Methods". 
The enterprise Vivisimo (Taylor, 2007) takes the same approach as GoPubMed by displaying categorisation of search results in a tree structure. With the product "Clusty", Vivisimo offers a meta search engine which groups similar results together into clusters. Still, the approach differs from GoPubMed as Clusty does not use a controlled vocabulary to index documents. Representative labels are identified from each cluster. Another example of an ontology-based search engine is Textpresso (Müller et al., 2004) which was built for scientific literature on C. elegans and selected others domains. The documents are indexed with biological concepts and relations based on a flat list of 101 concepts. EBIMed (Rebholz-Schuhmann et al., 2007), a tool developed by the European Bioinformatics Institute, identifies associations between UniProt protein/gene names, Gene Ontology annotations as well as Drugs and Species. Here, results are presented in chart form; and sentences supporting the associations are cited. The knowledge retrieval tool iHOP (Hoffmann and Valencia, 2005) hyperlinks Medline/ PubMed articles via protein or gene names. The user can query for a gene or protein and receives answers in form of sentences suggesting interactions with another gene/protein. The sentences are marked up with MeSH terms as well.

To summarize, whereas different biomedical semantic search tools already exist, they do not cover topics with relevance to alternative methods. Go3R, on the other hand, not only has a 3Rs specific ontology enabling targeted retrieval of 3Rs relevant information. Furthermore, it is designed to search the entire internet in the medium term, including specialised added-value databases like AnimAlt-ZEBET and ECVAM/DB-ALM, and not only in PubMed.

\subsection{How does Go3R solve current technological problems of conventional search engines?}

Go3R brings together the 3Rs relevant expert knowledge of many experts in the ontology and processes this knowledge so that it becomes available for all potential users in the intelligent table of contents presented alongside the individual search retrievals. By navigating through the intelligent table of contents, Go3R enables users to specifically focus on those pieces of information on alternative methods relevant for the given search query from within vast search results. Due to the semantic search technology, users will also be able to retrieve relevant information that they have not explicitly searched for.

First use scenarios to test the Go3R search engine and the underlying 3Rs ontology during the feasibility study confirmed that Go3R in fact serves to improve searches on alternative methods in accordance with the 3Rs principle. Go3R allows retrieving relevant information in a fast and targeted manner. Additionally, this relevant information can be sorted in compliance with selected subset topics (e.g. types of cells or cell lines used, endpoints determined during cell culture test methods or chemical groups of substances).

Search results obtained with Go3R are more comprehensive than those with conventional search engines. Already today, Go3R can automatically extend the query to synonyms of the search term (e.g. if the user searches for "eye irritation", the search engine automatically also looks for "ocular safety").
Go3R automatically extends the query to related topics and thus is able to retrieve relevant articles in which neither the search term itself nor its synonyms are mentioned (e.g. regarding a search for "Blood-Brain Barrier", Go3R will not only automatically include the synonyms "Blood-Brain Penetration", "BrainBlood Barrier", "Hematoencephalic Barrier", etc., but will also retrieve articles that contain none of these terms, but only 3 Rs relevant terms that are indirectly related to this topic, such as "Isolated Brain Microvessels").

Whereas it was decided to limit the search engine's data pool to PubMed during the development of the Go3R prototype, it is foreseen that Go3R will search the entire internet, including other literature databases, patents databases, etc., thereby enabling a comprehensive collection of $3 R$ s relevant information with one single search engine. The importance of extending Go3R's data pool to the entire internet was confirmed during the evaluation of the first use scenarios, which revealed that a significant proportion of relevant information on 3Rs methods is not indexed by PubMed.

Another important feature of the Go3R search engine is that it is designed to selectively present $3 R$ s relevant articles. With the help of the "3Rs relevant" filter, currently available in its beta version, the search engine automatically indicates those documents from the search result in which methodologies are depicted that make a contribution to the 3 Rs.

All in all, Go3R leads to transparent search results that can easily be evaluated by the searcher and by others. The categories and terms detected by the search engine are highlighted directly in the documents. This enables the user to evaluate the classifications and mappings at a glance and to quickly scan the contents of the document in regard to relevant statements.

\subsection{Which contribution to the $3 R s$ can Go3R make?}

Go3R aims to optimise the practice of determining either the availability or non-availability of 3Rs methods in all scientific areas in which animals are being used, except for education. It is expected that the efficient utilisation of alternative methods documented in the scientific literature will result in a quantifiable reduction of the numbers of animals used in scientific procedures. In order to substantiate this expectation and to be able to provide concrete figures regarding a reduction of laboratory animals as a result of improved information retrieval technologies, the further development of Go3R shall include concrete use scenarios determining the number of laboratory animals saved by each individual scenario due to the improved methodology for information retrieval. Thereby, evidence shall be provided that and how many laboratory animals are saved because of the improved information retrieval system in individual cases.

Regarding the avoidance of animal tests for regulatory purposes, e.g. to meet the requirements of the EU Chemicals Regulation (Commission of the European Communities, 2006) or those of the EU legislation on plant protection products (Commission of the European Communities, 1991), researchers both have to search for existing data in order to avoid repetitive animal testing and for relevant 3 Rs methodologies. The importance of thorough internet searches for existing data on toxicological 
endpoints in preventing animal testing has been confirmed during the United States High Production Volume Chemicals Programme (Nicholson et al., 2004).

Go3R can make a significant and unique contribution to finding both types of information. With the help of its detailed ontology branches on chemical substances, information on existing data can be extracted and sorted in a fast and transparent manner, while the information on available alternative methods can be extracted and sorted with the respective ontology branches in which the 3 Rs relevant knowledge is mapped.

\subsection{Which steps are required to further improve Go3R?}

While the Go3R search engine prototype available on the internet already has the potential to improve internet searches on alternative methods, more work is necessary to turn the Go3R prototype into a mature search engine that allows comprehensive 3 Rs relevant search results in all areas of biomedical research.

This goal should be pursued in a two tracked endeavour. Both the search engine and its underlying ontology require further development.

- As regards the further development of the ontology, important 3Rs relevant branches (e.g. "3Rs Methods in the Life Sciences", "Methodologies", "Biological Material and Organisms for Animal Use Alternatives") require detailed further editing by adding a plethora of additional terms. Each new term has to be defined and labelled precisely; and relevant synonyms have to be determined and added into the ontology just as their direct and indirect correlations to other terms and branches of the ontology.

- As regards the further development of the search engine, for all terms which cannot be associated unambiguously with terminology appearing in text and especially for all terms which do not appear literally in text but capture its topic, hand indexing needs to be done in order to decide whether a document mentions or does not mention the respective term.

Detailed mapping of the area of fundamental biomedical research in the ontology is likely to pose a special challenge. In this scientific area, concrete test methods - with specific names that could easily be tracked by the search engine - oftentimes do not exist, but only scientific approaches or measures making a contribution to the $3 \mathrm{Rs}$ for the given scientific purpose. The mapping of such approaches in the ontology is a special challenge requiring very detailed case-by-case defining and processing of the relevant terms and concepts so that the search engine can learn to identify the 3 Rs relevant scientific approaches or measures.

Equally important, the Go3R search engine has to continuously prove its worth in practice. The more scientists use Go3R and submit their feedback back to the editors of Go3R, the better the search engine will become. A software tool is in preparation which will allow a case-by-case document specific feedback to be expressed and conveyed with a few mouse clicks.

The development of an ontology is an ongoing process requiring continuous elaboration to keep the ontology up-to-date. Go3R has been made available free of charge in order to be ac- cessible worldwide by all potential users. The editors of Go3R have the vision to turn Go3R into a global community platform bringing together the 3 Rs relevant knowledge of experts from all over the world. The more knowledge is flowing into the search engine, the better it will become - with the aim to replace, reduce and refine animal experimentation all over the world.

\section{References}

Note: All websites, also those quoted in the text of the article, were accessed in January 2009.

Berger, A. L., Della Pietra, S. D. and Della Pietra, V .J. D. (1996). Maximum Entropy Approach to Natural Language Processing. Computational Linguistics 22(N1), 39-71.

BMELV (2007). German Federal Ministry for Nutrition, Agriculture and Consumer Protection (BMELV). Tierversuchszahlen 2007 [Numbers of Animals Used in Scientific Procedures in 2007]. http://www.bmelv.de/cln_045/ nn_753004/SharedDocs/downloads/07-SchutzderTiere/ Tierversuchszahlen/2007-TierversuchszahlenGesamt.html

Commission of the European Communities (1986). Council Directive 86/609/EEC of 24 November 1986 on the approximation of laws, regulations and administrative provisions of the Member States regarding the protection of animals used for experimental and other scientific purposes. Official Journal $L$ 358, 1-28. http://eur-lex.europa.eu/LexUriServ/LexUriServ.d o? uri=CELEX:31986L0609:EN:HTML

Commission of the European Communities (1991). Council Directive 91/414/EEC of 15 July 1991 concerning the placing of plant protection products on the market. Official Journal $L$ 230, 1-32. http://eur-lex .europa.eu/LexUriServ/LexUriServ.d o? uri=CELEX:31991L0414:EN:HTML

Commission of the European Communities (2006). Regulation (EC) No 1907/2006 of the European Parliament and of the Council of 18 December 2006 concerning the Registration, Evaluation, Authorisation and Restriction of Chemicals (REACH), establishing a European Chemicals Agency, amending Directive 1999/45/EC and repealing Council Regulation (EEC) No 793/93 and Commission Regulation (EC) No $1488 / 94$ as well as Council Directive 76/769/EEC and Commission Directives 91/155/EEC, 93/67/EEC, 93/105/EC and 2000/21/EC. Official Journal L 396, 1-849. http://eur-lex. europa.eu/LexUriServ/LexUriServ.do?uri=OJ:L:2006:396:0 001:0849:EN:PDF

Commission of the European Communities (2008). Proposal for a Directive of the European Parliament and of the Council on the protection of animals used for scientific purposes. COM/2008/0543 final - COD 2008/0211, 5 November 2008. 88 pp. http://eur-lex.europa.eu/LexUriServ/LexUriServ.do?u ri=COM:2008:0543:FIN:EN:PDF

Doms, A. and Schroeder, M. (2005). GoPubMed: exploring PubMed with the Gene Ontology. Nucleic Acids Res. 1(33) (Web Server issue), W783-6.

Fauser, B. (2007). Parliamentarian Petition of MP Beate Fauser and others and statement thereupon by the Minister for the 
Environment regarding the REACH Regulation. Parliament of the Federal State of Baden-Wuerttemberg. - Antrag der Abg. Beate Fauser u. a. FDP/DVP und Stellungnahme des Umweltministeriums zur REACH Chemikalienverordnung, Landtag von Baden-Württemberg Drucksache 14 / 116614. Wahlperiode, 19.04. 2007.

German Federal Government (2006). German Animal Welfare Act. Tierschutzgesetz publ. 18.5.2006. BGB1. I S. 1206, ber. S 1313. http://www.gesetze-im-internet.de/bundesrecht/ tierschg/gesamt.pdf

Grune, B., Fallon, M., Howard, C. et al. (2004). Report and recommendations of the international workshop "Retrieval approaches for information on alternative methods to animal experiments". ALTEX 21 (3), 115-127.

Hakkinen, P. J. and Green, D. K. (2002). Alternatives to animal testing: information resources via Internet and world wide web. Toxicology 173, 3-11.

Höfer, T., Gerner, I., Gundert-Remy, U. et al. (2004). Animal testing and alternative approaches for the human health risk assessment under the proposed new European chemicals regulation. Arch. Toxicol. 78, 549-564.

Hoffmann, R. and Valencia, A. (2005). Implementing the iHOP concept for navigation of biomedical literature. Bioinformatics 21 Suppl. 2, ii252-258.

Martijn, J., Schuemie, J. A. and Kors, B. M. (2005). Word sense disambiguation in the biomedical domain: an overview. $J$. Computational Biology 12(5), 554-565.

Müller, H. M., Kenny, E. E. and Sternberg, P. W. (2004). Textpresso: An Ontology-Based Information Retrieval and Extraction System for Biological Literature. PLoS Biology 2(11), e309. doi:10.1371/journal.pbio.0020309

Nicholson, A., Sandler, J. and Seidle, T. (2004). An evaluation of the US high production volume (HPV) chemical-testing programme: a study in (ir)relevance, reduncancy and retro thinking. ATLA 32 Suppl. 1, 335-341.

Rebholz-Schuhmann, D., Kirsch, H., Arregui, M. et al. (2007). EBIMed--text crunching to gather facts for proteins from Medline. Bioinformatics 23(2), e237-244.

Russell, W. M. S. and Burch, R. L. (1959). The principles of humane experimental technique. London, UK: Methuen.

Taylor, D. P. (2007). An integrated biomedical knowledge extraction and analysis platform: using federated search and document clustering technology. Methods Mol. Biol. 356, 293-300.

TEWG (2003). Technical Expert Working Group for the revision of Directive 86/609/EEC on the protection of animals used for experimental and other scientific purposes. Final report of the Sub-Group Ethical Review. http://ec.europa.eu/ environment/chemicals/lab_animals/pdf/finalreportethicalreviewprocess.pdf

Xu, H., Markatou, M., Dimova, R. et al. (2006). Machine learning and word sense disambiguation in the biomedical domain: design and evaluation issues. BMC Bioinformatics 7 , 334-350.

\section{Acknowledgements}

The authors gratefully acknowledge the National German Centre for Documentation and Evaluation of Alternatives to Animal Experiments (ZEBET) at the German Federal Institute for Risk Assessment (BfR) in Berlin for the funding of the feasibility study (FK 3-1328-201) that lead to the creation of the Go3R.org semantic search engine prototype.

In this context, Dr. Manfred Liebsch and Dr. Andrea Seiler from ZEBET at the BfR are thanked for their valuable advice on all issues concerning alternatives to animal testing and, specifically, cell culture methodologies, and for detailed discussions on a large number of branches of the ontology prototype. We are also indebted to Dr. Dieter Wolff (BfR, Berlin) and Dr. Uwe Klemm (Department of Immunology, Max Planck Institute for Infection Biology, Berlin) for their advice on the Go3R ontology branches Animal Care and Handling, Animal Conditions, Physiological and Psychological, Animal Experiments and Laboratory Animals.

Transinsight $\mathrm{GmbH}$ is thanked for additional funding and the provision of technology necessary for the internet presence of the Go3R search engine. The technical support of Mr. Matthias Leis (Transinsight $\mathrm{GmbH}$ ) during the publication of the article is gratefully acknowledged. The financial support of the BASF and especially Dr. Robert Landsiedel, Head of the Short Term Toxicology Department of BASF, helping to provide the service Go3R on the internet, is also highly appreciated.

\section{Correspondence to}

Dr. Ursula G. Sauer

Scientific Consultancy - Animal Welfare

Hallstattfeld 16

85579 Neubiberg

Germany

Tel.: +49-89-66090717

e-mail: ursula.sauer@sauerug.de 